\title{
ASSOCIAÇÃO DO POLIMORFISMO DO GENE DA ENZIMA CONVERSORA DA ANGIOTENSINA COM DADOS ECOCARDIOGRÁFICOS EM JOVENS NORMOTENSOS FILHOS DE HIPERTENSOS
}

\author{
Roberto Alexandre franken*, Marcelo Bellesso, Adriana M. Cavazin, Igor Bastos Polônio, \\ Euclides Mattheucci, José Varga \\ Trabalho realizado na Faculdade de Ciências Médicas da Santa Casa de São Paulo, São Paulo, SP.
}

RESUMO - OBJETIVOS. Os autores objetivaram no presente estudo avaliar o polimorfismo da enzima conversora da angiotensina com dados do ecocardiograma de jovens estudantes de Medicina, filhos de hipertensos, comparados com jovens filhos de normotensos.

Métodos. Foram estudados 80 jovens normotensos divididos em dois grupos: $\mathbf{4 0}$ filhos normotensos de pais hipertensos e 40 filhos normotensos de pais hipertensos. Critérios de exclusão foram hipertensão arterial, fumo, obesidade, uso de contraceptivos orais. Uso crônico de medicamentos e presença de qualquer doença. Os alunos foram incluídos entre 1994 e 1996.

Cinqüenta alunos foram submetidos a ecocardiograma transtoráxico. A análise estatística foi feita através do teste $T$ de Student. A avaliação do polimorfismo do gene da enzima conversora da angiotensina foi feita nos 80 alunos conforme segue: I) $5 \mathrm{ml}$ de sangue em tubo contendo EDTA, 2) extração do DNA, 3) medida da concentração do DNA por eletroforese, 4) reação em cadeia de polimerase com "primer" do gene da enzima conversora da angiotensina, 5) análise do polimorfismo do gene da enzima conversora da angiotensina através da eletroforese e 6) análise estatística através do teste do Qui-quadrado.

Resultados. 0 grupo de estudantes filhos de hipertensos mostraram maior espessura do septo interventricular $(7,82 \mathrm{~mm}+/$ $0,69$ contra $7,38+/-0,8, p<0,05)$. Por outro lado não encontramos diferenças entre os grupos em relação ao genótipo do gene da enzima conversora. Filhos de hipertensos DD $42,5 \%$, DI 37,5\%, II $20 \%$ contra filhos de normotensos: DD $37,5 \%$, DI $32,5 \%$, II $30 \%$, $(p=0,58)$. Não encontramos mesmo diferenças quando considerados os alelos. 0 grupo com pais hipertensos D $61,25 \%$, I 38,75\%, contra grupo com pais normotensos D 53,75\%, I 46,25\% $(p=0,33)$. Dividimos o grupo em dois, considerando a média da espessura do septo interventricular e a massa do ventrículo esquerdo e também não encontramos diferenças: estudantes com pais hipertensos com septo > 7,82mm; DD 32\%, DI 24\%, II 20\% contra septo < 7,82mm; DD $86 \%$, DI I2\%, II $4 \%(p=0,7)$. Naqueles com pais normotensos septo > 7,38mm: DD28\%, DII2\%, II I2\%, contra septo < 7,38mm: DDI6\%, DI6\%, II I6\% $(p=0,59)$. Em relação à massa ventricular em filhos de pais hipertensos: massa > I31,52g: DD 20,69\% DI 13,79\%, II 6,9\% contra massa < I3I,52g: DD 24,24\%, DI 17,24\%, II I7,24\% $(p=0,72)$. No grupo de alunos filhos de pais normotensos massa $>$ II7,IIg: DD 30,43\%, DI 8,7\%, II 8,7\% contra massa < II7,IIg: DD $13,04 \%$, DI $21,74 \%$, II $17,39 \%(p=0,17)$

Conclusão. Encontramos diferenças entre a espessura do septo interventricular de estudantes normotensos filhos de hipertensos e filhos de normotensos. Por outro lado, não encontramos diferenças entre os grupos considerando o polimorfismo do gene da enzima de conversão da angiotensina, assim como qualquer relação do gene da enzima de conversão da angiotensina e a espessura do septo e massa ventricular.

Unitermos: Hipertensão arterial. Gene da Enzima de Conversão da Angiotensina. Hipertrofia ventricular.

\section{INTRODUÇÃO}

A hipertensão arterial essencial (HAE) é uma enfermidade multifatorial e poligenética' extremamente freqüente, acometendo aproximadamente dois terços de toda a população acima de 65 anos, sendo também o principal fator de risco para as doenças cardiovas-

\footnotetext{
*Correspondência:

Rua Franco da Rocha, 163, Ap. 52

Cep: 05015-040 - São Paulo - SP

Tel. (11) 221-0325

E-mail: rafsf@uninet.com.br
}

culares. A hipertrofia cardíaca que convencionalmente é vista como uma adaptação estrutural e funcional em níveis pressóricos elevados pode envolver uma predisposição familiar' Estudo ecocardiográfico em nosso serviço ${ }^{2}$ mostrou em filhos de hipertensos, mesmo na vigência de pressão arterial normal, maior espessura do septo e parede posterior do ventrículo esquerdo quando comparado aos filhos de normotensos.

Outros fatores independentes do estresse hemodinâmico tais como: obesidade, resistência à insulina e predisposição genética podem promover hipertrofia cardíaca. Sabemos que o sistema renina angiotensina é um importante fator regulador da pressão arterial. Embora seu envolvimento na patogênese da hipertensão renovascular esteja bem documentado, na hipertensão arterial essencial (HAE) nem sempre hipertensos apresentam aumento dos níveis plasmáticos de renina ${ }^{3,4}$.

O polimorfismo do intron 16 do gene da enzima conversora de angiotensina (ECA) consiste em dois alelos: deleção (D) com aproximadamente 190 bases nitrogenadas e inserção (I) com 490 bases nitrogenadas. Foi demonstrado 
que indivíduos com genótipo DD possuem maior nível plasmático de ECA, correspondendo com maior nível plasmático de angiotensina II. Assim, os indivíduos com genótipo DI possuem níveis intermediários e os indivíduos com genótipo II, níveis inferiores ${ }^{5,6}$.

Seria, pois, de se admitir que o aumento da resistência vascular periférica causada pela vasoconstrição provocada pelo aumento plasmático de angiotensina II, assim como pela maior inibição da bradicinina (potente vasodilatador) em indivíduos com genótipo DD, contribuiria para o aumento da pressão arterial, porém há inúmeras controvérsias frente à associação do polimorfismo do gene da ECA em relação a $H A E^{I, 4,7}$.

\section{Objetivos}

Analisar o polimorfismo do gene da ECA em jovens normotensos, filhos de pais hipertensos, correlacionando com dados ecocardiográficos (espessura do septo interventricular, espessura da parede posterior do ventrículo esquerdo e massa do ventrículo esquerdo).

\section{Casuística}

Foram selecionados 80 acadêmicos de Medicina por meio de questionário e entrevista, que inqueria sobre a presença de hipertensão arterial entre os pais, como também medicação usada. Estes dados foram obtidos através de anamnese com os alunos. Considerando tratar-se de estudantes de Medicina, a hipertensão arterial nos pais foi informada pelo aluno, os pais não foram examinados ou mesmo entrevistados. Foram excluídos indivíduos hipertensos, tabagistas, obesos, usuárias de anticoncepcional oral ou de medicação crônica e portadores de alterações clínicas preexistentes. Este grupo foi analisado em relação ao polimorfismo do gene da ECA.

Em 50 destes indivíduos foi realizado ecocardiograma bidimensional transtorácico.

\section{Métodos}

Os alunos foram submetidos ao exame clínico, ecocardiograma transtorácico e análise do polimorfismo do gene da ECA.

O exame físico foi constituído por medida da PA, freqüência cardíaca, ausculta pulmonar e cardíaca, visando descartar os indivíduos com alterações clínicas preexistentes.

\begin{tabular}{lccc}
\hline \multicolumn{4}{c}{ Tabela I - Distribuiçãa por grupo e sexo dos acadêmicos } \\
\hline \multirow{4}{*}{ Homens } & $\frac{\text { Mulheres }}{17}$ & $\frac{\text { Total }}{4 \mid}$ \\
FH & 24 & 23 & 40 \\
FN & 17 & 40 & \\
Total & 41 & &
\end{tabular}

FH: filhos de pais hipertensos; FN : filhos de pais normotensos

\begin{tabular}{|c|c|c|}
\hline & FH & FN \\
\hline $\begin{array}{l}\text { Idade } \\
\text { IMC (kg/m2) } \\
\text { PASr (mmHg) } \\
\text { PADr }\end{array}$ & $\begin{array}{c}18,73 \pm 1,41 \\
21,80 \pm 2,55 \\
109,26 \pm 16,18 \\
70,48 \pm 9,54\end{array}$ & $\begin{array}{c}|8,78 \pm 1,5| \\
22,64 \pm 1,9 \mid \\
108,33 \pm \mid 2,05 \\
74,66 \pm 10,07\end{array}$ \\
\hline
\end{tabular}

FH: filhos de pais hipertensos; FN : filhos de pais normotensos

A pressão arterial foi medida de acordo com as normas das Diretrizes Brasileiras de Hipertensão Arterial com esfigmomanômetro de coluna de mercúrio (Tabelas | e 2).

Foi realizado ecocardiograma transtorácico em 50 indivíduos, sendo 25 (50\%) filhos de hipertensos e o restante filhos de normotensos. $O$ equipamento usado foi 0 Toshiba modelo SSH - $140^{A}$ e os dados foram obtidos a partir de aquisições no modo $\mathrm{M} \mathrm{e}$ bidimensional. As medidas obedeceram as normas de Sociedade Americana de Ecocardiografia sempre realizadas pelo mesmo examinador.

Os dados obtidos foram avaliados pelo teste estatístico de T-Student.

\section{A análise do polimorfismo do gene} da ECA, constituiu-se de várias etapas:

I) Coletou-se $5 \mathrm{~mL}$ de sangue dos acadêmicos em tubo de ensaio contendo EDTA.

2) Extraiu-se DNA dos leucócitos das amostras.

3) Constatou-se e avaliou-se a concentração de DNA de cada amostra pela técnica de eletroforese.

4) Promoveu-se a técnica de amplificação do gene da ECA pelo método de reação de polimerização em cadeia (PCR).

5) Analisou-se o polimorfismo do gene da ECA por eletroforese.

6) Estudou-se de modo comparativo os dados obtido pelo tese de "Qui-square" a freqüência dos genótipos em relação aos grupos como também com os dados ecocardiográficos.
Extração de DNA pelo sangue: resumidamente o método é constituído por separação do plasma e dos elementos figurados por centrifugação; hemólise pelo uso de TTKMI, TKMI e centrifugação; lise de leucócitos pelo uso de TKM2, SDS e banho-maria a $65^{\circ} \mathrm{C}$; precipitação das proteínas citoplasmáticas dos leucócitos através de $\mathrm{NaCl}$ e centrifugação; finalmente, precipitaçãao do DNA pelo uso de álcool $70 \%$ e 100\% e centrifugação. A conservação do DNA extraído é feita na temperatura de $-6^{\circ} \mathrm{C}$.

Constatação e análise da concentração de DNA: usa-se a técnica de eletroforese em placa de gel de agarose a $1 \%$ na ddp de $80 \mathrm{mV}$. Em cada compartimento do gel é colocada uma solução composta por $2 \mathrm{~mL}$ da solução com DNA a ser avaliado, $3 \mathrm{~mL}$ de água destilada e ImL de Loading Buffer (corante). Após a eletroforese, coloca-se 0 gel sobre suporte que emite raio ultra-violeta iluminando o DNA. A concentração do DNA de cada amostra varia de acordo com o tamanho da banda iluminada.

Técnica de PCR: é necessário para promover essa técnica o uso de solução contendo $3 \mathrm{~mL}$ da solução de DNA na concentração de 50 a 100 ng/mL; 3,0mL de Primer PI* e P2**; I,5mL de dNTP (bases nitrogenadas); $3,0 \mathrm{~mL}$ de tampão; 2,0 mL MgCl2; 0,5 mL de taq polimerase; e 9,2mL de água ultra-destilada. Feita a solução, colocá-la em termociclador que sofrerá "Hot start" ( 10 minutos na temperatura de $\left.100^{\circ} \mathrm{C}\right)$ e, após, passará por 35 ciclos 
Franken RA et al.

contendo cada ciclo três fases: $94^{\circ} \mathrm{C}$ por um minuto (desnaturação do DNA, rompimento das pontes de hidrogênio); $55^{\circ} \mathrm{C}$ por um minuto (anelamento, os primers se hibridam em posições específicas); $72{ }^{\circ} \mathrm{C}$ por um minuto (extensão, ação da Taq polimerase sintetizando fitas de DNA). É necessário salientar que os primers são seqüências específicas de oligonucleotídeos que reconhecem o início do gene da ECA.

\section{*PI: sense:}

\section{5'CTGGAGACCACTCCCATCCTTTCT3';}

\section{** P2: antisense:}

5'ATGTGGCCATCACATTCGTCGTCAGAT3'

Análise do polimorfismo do gene: usa-se novamente o método de eletroforese com placa de gel de agarose a $2 \%$ na ddp $100 \mathrm{mV}, 60 \mathrm{~mA}$. Cada compartimento do gel contém solução com: $4 \mathrm{~mL}$ de Loading Buffer e $25 \mathrm{~mL}$ da solução que contém DNA amplificado. Coloca-se em um compartimento a solução de $6 \mathrm{~mL}$ de Ladder I,2,3, que agirá como controle das bandas de DNA a serem avaliadas.

Após a eletroforese, posiciona-se o gel sobre suporte que emite raio UV e assim constataremos o polimorfismo do gene devido à migração ocorrida. O alelo deleção migrará mais comparado ao alelo inserção por ser mais leve (190 bases nitrogenadas).

\section{Resultados}

A distribuição da freqüência dos genótipos em relação aos grupos não mostrou diferença significativa $(p>0,05)$. Observa-se menor porcentagem de indivíduos com genótipo II no grupo de filhos de normotensos (Tabela 3).

Já a distribuição dos alelos do gene da ECA em relação aos grupos não nos mostrou significância estatística. Houve maior porcentagem do alelo I no grupo de filhos de normotensos. $\mathrm{O}$ alelo $\mathrm{D}$ teve porcentagem maior no grupo de filhos de hipertensos (Tabela 4).

Foi encontrada diferença significativa na espessura do septo interventricular e da parede posterior do ventrículo esquerdo entre os grupos de filhos de hipertensos e de normotensos. No segundo grupo houve maior valor destes parâmetros (Tabelas 5 e 6).

Não houve diferença estatisticamente significante na distribuição das massas do ventrículo esquerdo em relação aos genótipos e aos grupos (Tabela 7).

\begin{tabular}{lcc}
\hline \multicolumn{3}{c}{ Tabela 3 - Distribuição da freqüência dos genótipos em relação aos grupos } \\
\hline Genótipolgrupo & FH & $\frac{\text { FN }}{\mid 5(37,5 \%)}$ \\
DD & $\mid 7(42,5 \%)$ & $13(32,5 \%)$ \\
$D \mid$ & $\mid 5(37,5 \%)$ & $\mid 2(30 \%)$ \\
$\|$ & $8(20 \%)$ & \\
\hline
\end{tabular}

$p=0,58$; FH: filhos de pais hipertensos; FN: Filhos de pais normotensos; DD: deleção-deleçăo; DI: deleção-inserçãa; II: inserção-inserção.

Tabela 4 - Distribuição dos alelos do gene da ECA em relação aos grupos

\begin{tabular}{lll}
\hline Alelolgrupo & FH & FN \\
\cline { 2 - 2 } & $49(61,25 \%)$ & $43(53,75 \%)$ \\
$\mathrm{I}$ & $31(38,75 \%)$ & $37(46,25 \%)$ \\
\hline
\end{tabular}

$p=0,33$ FH: filhos de pais hipertensos; FN: Filhos de pais normotensos; D: deleçãa; I: inserçãa

Tabela 5 - Distribuição das médias dos parâmetros do exame ecocardiográfico

\begin{tabular}{|c|c|c|}
\hline & $\begin{array}{l}\text { Filhos de hipertensos } \\
\text { (médias) }\end{array}$ & $\begin{array}{l}\text { Filhos de normotensos } \\
\text { (médias) }\end{array}$ \\
\hline D.D.V.E. $(\mathrm{mm})$ & $46,25 \pm 4,16$ & $45,34 \pm 4,48$ \\
\hline D.S.V.E. (mm) & $28,82 \pm 3,54$ & $28,38 \pm 3,18$ \\
\hline V.D.F. $(\mathrm{mL})$ & $101,33 \pm 24,04$ & $93,92 \pm 26,18$ \\
\hline V.S.F. $(m L)$ & $26,88 \pm 9,98$ & $23,53 \pm 7,88$ \\
\hline Massa V.E. (g) & $|3|, 52 \pm 26,8 \mid$ & $|17,1| \pm 28,37$ \\
\hline Septo $(\mathrm{mm})$ **⿻丷木 & $7,82 \pm 0,69$ & $7,38 \pm 0,80$ \\
\hline E.P.P. $(\mathrm{mm})$ *** & $7,85 \pm 0,59$ & $7,42 \pm 0,75$ \\
\hline D.V.D (mm) & $21,25 \pm 2,82$ & $19,65 \pm 2,39$ \\
\hline D.A.E. (mm) & $30,35 \pm 3,00$ & $29,80 \pm 3,46$ \\
\hline Aorta (mm) & $25,92 \pm 2,91$ & $25,00 \pm 3,11$ \\
\hline F.Ej. (\%) & $74,64 \pm 5,25$ & $73,23 \pm 8,22$ \\
\hline F.Enc $(\%)$ & $38,26 \pm 3,41$ & $38,66 \pm 9,80$ \\
\hline I.M. (g/m2) & $73,35 \pm 13,16$ & $74,76 \pm 26,87$ \\
\hline V/M (mL/g) & $0,76 \pm 0,12$ & $0,80 \pm 0,17$ \\
\hline
\end{tabular}

Valores expressos em médias $\pm d p, p^{* *}<0,05$

D.D.V.E. = Diâmetro diastólico do ventrí́culo esquerdo; D.S.V.E. = Diâmetro sistólico do ventrí́culo esquerdo; V.D.F. =; Volume diastólico final; V.S.F. = Volume sistólico final; Massa V.E. $=$ Massa do ventrículo esquerdo; Septo $=$ Septo; interventricular; E.P.P. $=$ Espessura da parede posterior; D.V.D. = Dimensão do ventrículo direito; D.A.E. = Dimensão do átrio esquerdo; F.ej = Fração de ejeção; F.Enc. = Fração de encurtamento; I.M. = Índice de massa; V / M = Relação volume massa. FH: Filhos de pais hipertensos; FN: Fillhos de pais normotensos

Tabela 6 - Distribuição da frequêencia do genótipo em relação à média da espessura do septo interventricular entre os grupos

\begin{tabular}{lcccc} 
Genótipo & $\mathbf{F H}>7,82 \mathrm{~mm}^{*}$ & $\frac{\mathbf{F H}<7,82 \mathrm{~mm}^{* *}}{\mathrm{FN}>7,38 \mathrm{~mm}^{* * *}}$ & $\frac{\mathrm{FN}<7,38 * * * *}{4}$ \\
DD & 8 & 2 & 3 & 4 \\
DI & 6 & 3 & 3 & 4 \\
$\|$ & 5 & 1 & 3 & 4 \\
\hline
\end{tabular}

*FH 7,82 mmm: filhos de pais hipertensos que apresentaram a espessura do septo interventricular maior que a média*** $\mathrm{FH}<7,82 \mathrm{~mm}$ : filhos de pais hipertensos que apresentaram a espessura do septo interventricular menor que a média $(p=0,70)$, *** $\mathrm{FN}>7,38 \mathrm{~mm}$ : filhos de pais normotensos que apresentaram a espessura dos septo interventricular maior que a média; ***** $\mathrm{FN}<7,38 \mathrm{~mm}$ : filhos de pais normotensos que apresentaram a espessura dos septo interventricular menor que a média; FN ( $P=0,59)$ DD: deleção-deleçãa; Dl: deleção-inserçăo; Il: inserçãoinserção. 
Tabela 7 - Distribuição das médias da massa do ventrículo esquerdo em relação ao genótipos e os grupos

\begin{tabular}{|c|c|c|c|c|}
\hline Genótipo & $\mathrm{FH}>|3|, 52 \mathrm{~g}^{*}$ & $\mathrm{FH}<\mid 31,52 * *$ & $\mathrm{FN}>117, \mathrm{I} \mid * * *$ & $\mathrm{FN}<117, \mathrm{I} \mid * * * *$ \\
\hline $\mathrm{DD}$ & 6 & 7 & 7 & 3 \\
\hline $\mathrm{Dl}$ & 4 & 5 & 2 & 5 \\
\hline$\|$ & 2 & 5 & 2 & 4 \\
\hline$\|$ & 5 & 1 & 3 & 4 \\
\hline
\end{tabular}

*FH $>|3|, 52$ g: filhos de pais hipertensos que apresentaram a massa do ventrículo esquerdo maior que a média; $* * F H<|3|, 52$ : filhos de pais hipertensos que apresentaram a massa do ventrículo esquerdo menor que a média $(p=0,70)$, ***** $F N>\| 17,||$ g: filhos de pais normotensos que apresentaram a massa do ventrículo esquerdo maior que a média; ***** $\mathrm{FN}<1|\mathrm{I}, \mathrm{I}| \mathrm{Ig}$ : filhos de pais normotensos que apresentaram a massa do ventrículo esquerdo menor que a média; DD: deleçãa-deleção; DI: deleção-inserçãa; II: inserção-inserção; $F H(p=0,72) ; F N(p=0,17)$

\section{Discussão}

O polimorfismo de deleção do gene da enzima conversora de angiotensina tem sido associado a diversos eventos fisiopatológicos e de morbi-mortalidade das doenças cardiovasculares, entretanto, neste trabalho, nos restringiremos a correlacionar o polimorfismo com hipertensão arterial essencial (HAE) e com hipertrofia ventricular esquerda (HVE).

\section{Hipertrofia ventricular esquerda}

A fisiopatologia da hipertrofia do ventrículo esquerdo (VE) tem sido alvo de intrigantes pesquisas. Alguns autores comprovaram que indivíduos normotensos filhos de hipertensos apresentam ventrículo esquerdo dilatado e hipertrofiado quando comparados a filhos de normotensos ${ }^{8,9}$. Devereux $x^{8}$ chegou a considerar que a massa do VE poderia prever o desenvolvimento de HAE em indivíduos com história familiar da doença.

Foi observado em nosso estudo que apesar dos filhos de hipertensos apresentarem massa cardíaca similar aos filhos de normotensos, a espessura do septo interventricular e da parede posterior do VE é significativamente maior, apesar de ainda dentro dos valores normais. Acreditamos que este fato indique uma tendência, uma vez que nossa população é constituída de jovens ${ }^{2}$. Estes resultados estão de acordo com os encontrados por Hansen ${ }^{10}$, que também não observou diferenças na massa cardíaca. Contraditoriamente, Alleman"I não encontrou nenhuma diferença significativa nos parâmetros ecocardiográficos estudados.

\section{Polimorfismo do gene da ECA}

Em nosso estudo as frequêencias dos alelos D e I (57,5\% e $42,5 \%$, respectivamente) foram semelhantes às encontradas por
O'Donnel et al. ${ }^{12}$ que estudaram uma população de 3095 indivíduos caucasianos. Entretanto, as freqüências dos genótipos DD e DI foram diferentes.

Por outro lado, Ishigami et al. ${ }^{13}$ observaram, em japoneses, diferenças nas freqüências dos alelos D e I (37,7\% e 62,3\%, respectivamente).

\section{Hipertensão arterial e polimorfismo do gene da ECA}

Existe atualmente grande controvérsia na associação do polimorfismo do gene da ECA com hipertensão arterial sistêmica.

Embora em nossa análise não havia indivíduos hipertensos não foi encontrado associação entre as freqüências dos alelos e dos genótipos em relação aos grupos FH e FN. Chrostowska et al..14, avaliando jovens normotensos filhos de hipertensos, constataram associação entre o alelo D com o aumento da pressão arterial em teste de monitorização ambulatorial da pressão arterial em 24 horas. Inúmeros artigos foram publicados avaliando em estudos caso-controle (normotenso $X$ hipertensos) não tendo sido evidenciado correlação em relação aos genótipos e alelos ${ }^{13-17}$. Chiang et al. ${ }^{18}$, avaliando população chinesa, encontraram correlação entre os alelos e hipertensão arterial, mas não entre os genótipos.

Foram encontradas correlações na pressão arterial diastólica nos indivíduos do sexo masculino com genótipo DD numa população geral de 3095 pessoas $^{12}$; Nakano et al. ${ }^{15}$, em estudo caso-controle evidenciaram que o alelo D está associado com hipertensão arterial precoce e Abbud et al. ${ }^{17}$ constataram correlação do genótipo DD em relação à hipertensão arterial.

\section{Hipertrofia e polimorfismo do gene da ECA}

Em nosso trabalho não houve correlação do polimorfismo do gene da ECA com a maior espessura do septo interventricular encontrada nos filhos de hipertensos comparada aos filhos de normotensos, a exemplo de Lindpainter et al..$^{19}$ que, ao estudarem 2.439 indivíduos provenientes do estudo de Framingham, não acharam correlação entre 0 genótipo da ECA com a massa do VE, nem com a prevalência de HVE.

Em concordância com 0 estudo de Framingham, West et al. ${ }^{20}$ defendem que não se pode correlacionar a HVE com o polimorfismo do gene da ECA. Um dos argumentos desses autores é que há outros caminhos não dependentes da ECA para se gerar angiotensina II . Assim, a angiotensina II pode surgir do angiotensinogênio diretamente ou da angiotensina I, através da conversão da enzima quimase encontrada no tecido cardíaco.

Observações epidemiológicas demostram que muitos indivíduos com HVE têm pressão arterial normal, o que sugere que outros fatores, além da sobrecarga hemodinâmica, podem contribuir para a hipertrofia ${ }^{21}$.

Em contraste com o estudo de Framingham, alguns autores acharam associação positiva entre a HVE e o polimorfismo de deleção do gene da ECA.

Perticone et al. ${ }^{22}$, ao estudarem 140 indivíduos hipertensos não-tratados, acharam correlação entre o maior índice de massa ventricular esquerda e o genótipo DD do polimorfismo da ECA. Gaharavi et al. ${ }^{23}$, ao estudarem 67 pacientes hipertensos, constataram maior índice de massa ventricular esquerda nos genótipos DD e DI. O mesmo resultado foi encontrado por Nakano et al. ao estudarem 178 indivíduos com HAE ${ }^{15}$.

Além disso, alguns autores correlacionam a cardiomiopatia hipertrófica com maior freqüência do alelo $D^{7,8}$.

Em resumo, há ainda inúmeras controvérsias quanto a este assunto, o que requer maior número de pesquisas para a correlação de HVE com o polimorfismo do gene da ECA. Os diferentes trabalhos com diversas conclusões em relação ao assunto sugerem que, além do polimorfismo do gene da ECA, outros genes devem estar incluídos para o desenvolvimento da HAE e da HVE. 
Franken RA et al.

\section{Conclusão}

Nosso estudo permite concluir que, apesar de ter ocorrido diferença significativa da espessura do septo interventricular entre os grupos de $\mathrm{FH}$ e $\mathrm{FN}$, não houve correlação desse dado com o polimorfismo do gene da ECA, tanto ao se analisar os genótipos, quanto os alelos separadamente. Assim, infere-se deste estudo que outros fatores, além do polimorfismo do gene da ECA, podem ser responsáveis por esta diferença de espessura.

\section{SUMMARY}

\section{Association OF ANGIOTENSIN CONVER- TING ENZYME POLIMORPHISM AND ECOCAR- DIOGRAPHIC MEASURES IN YOUNG SIBLINGS OF HYPERTENSIVE PARENTS}

Objectives: To evaluate angiotensin converting enzyme gene (ACE) polymorphism with transthoracic bidimensional ecocardiogram of normotensive young medical students, siblings of hypertensive parents comparing them with those with normotensive parents.

Method: We had studied 80 normotensive youngs divided in two groups: Hypertensive parents' normotensive young medical students $40 \times$ Normotensive parents' and normotensive medical students. Exclusion criteria were hypertension, obesity, smoke, use of oral contraceptives, as well as those who use chronically drugs or the presence of any disease. The group has been enrolled between 1994 to 1996. 50 students made transthoracic bidimensional echocardiogram. The statistical analysis was done by "T-student" test. The evaluation of polymorphism ACE gene was studied in 80 people in each step: 1) $5 \mathrm{~mL}$ of blood in EDTA tube; 2) extraction of DNA; 3) evaluation of DNA concentration by eletrophoresis analyses; 4) Polymerase chain reaction with primer of ACE gene; 5) Analysis of polymorphism ACE gene by electrophoresis 6) Statiscal analysis by Chi-square test.

Results: The group of students with hypertesive parents presented thicker interventricular septum $(7.82 \mathrm{~mm} \pm 0.69$ against $7.38 \mathrm{~mm} \pm 0,8, p<0,05)$. On the other hand, we didn't find differences between the groups concerning ACE gene genotype: students with hypertensive parents DD:42.5\%, DI: 37.5\%, II: 20\% against Students with normotensive parents : DD: $37.5 \%$, Dl: $32.5 \%$, II: $30 \%,(p=0,58)$, in addition we also did not find differences concerning the alleles Group of hypertensive parents: D: $61.25 \%, 1: 38.75 \%$ versus normotensive parents: D: $53.75 \%$, I: $46.25 \%, p=0,33$. We divided these groups into two in relation to the mean thickness of interventricular septum and left ventricular mass and we did not find any difference: in students with hypertensive parents group septum $>7,82$ mm: DD: $32 \%$, Dl: $24 \%$, II: $20 \%$ x septum < 7,82 mm: DD: $8 \%$, Dl: $12 \%$, II: $4 \%, p=0,7)$ in normotensive parents group septum septum > 7,38mm : DD 28\%, DI: 12\%, II: 12\% X septum $<7,38 \mathrm{~mm}:$ DD: $16 \%$, Dl: 16\%, II: 16\%, $p=0,59)$. The study of the left ventricular mass in hypertensive parents group mass > 131.52g: DD: $20.69 \%$, DI: $13.79 \%$, II:6.9\% X mass < 131, 52g DD: $24.24 \%$, DI: 17.24\%, II: 17.24\%, ( $p=0,72)$ in normotensive parents group mass $>117, \mathrm{llg}: \mathrm{DD}: 30.43 \%$, Dl: 8.7\%, II: $8.7 \% X$ mass < $117,11 \mathrm{~g}: \mathrm{DD}:$ 13.04\%, DI, 21.74\%, II: 17.39\%, ( $p=0,17)$.

Conclusion: We found differences between the thickness of the interventricular septum of normotensive students sibling of hypertensive parents and normotensive parents. On the other hand we didn't find any difference between the two groups concerning the ACE gene polymorphism as well as any relation of ACE gene and thickness of interventricular septum and interventricular left ventricular mass. [Rev Assoc Med Bras 2004; 50(I): 62-7]

KEY WORDS: Hypertension. Angiotensin Converting Enzyme gene. Ventricular hypertrophy. CNPq.

Este trabalho obteve bolsa PIBIC do

\section{REFERÊNCIAS}

I. Dzau VJ, Krieger JE, Hutchinsons H. Molecular mechanisms in hypertension in Haber E molecular cardiovascular medicine. Sci Am |995:225-41.

2. Santos ARL, Santos AR, Giampetro ES et.al. Avaliação ecocardiográfica, ergométrica e perfil lipídico de jovens normotensos filhos de hipertensos Arq Bras Cardiol 1996; 67 (Supl I): I 27.

3. Fernandez Llama P, Poch E, Oriola J, Botey A De la Sierra A, Revert L, et al. Angiotensin converting enzyme gene I/D polymorphism in essential hypertension and nephroangiosclerosis; Kidney Int 1998; 53: 1743-7.

4. Mondorf UF, Russ A, Wieseman A, Herrero M, Oremek G, Lenz T. Contribution of angiotensin I converting enzyme gene polymorphism. To blood pressure regulation in essential hypertension. Am J Hypertens 1998 ; I I : 174-83.

5. Tiret L, Rigat B, Visvikis S, Breda C, Cambien F, Corvol P, et al. Evidence, from combined segregation and linkage analysis, that a variant of the angiotensin I-converting enzyme (ACE) gene controls plasma ACE levels. Am J Genet 1992; 5 |: 197-205.

6. Rigat B, Hubert C, Alhenc-Gelas F, AlhencGelas F, Cambien F, Corvol S, et. al An insertion/deletion polymorphism in the angiotensin converting enzyme gene accounting for half variance of serum enzyme levels. J Clin Invest 1990; 86: I343-6.

7. Vaská A, Soucek M, Znojil V, Rihácek I. Angiotensin l-converting enzyme and angiotensinogen gene interaction and prediction of essential hypertension. Kidney Int 1998; 53: | 479-82.

8. Devereux RB, Simone G, Karen MJ, Roman MJ, Laragh $J \mathrm{H}$. Left ventricular mass as a predictor of development of hypertension. Am J Hypertens 1991; 4:6039-75.

9. Dianzamba SB, DiPette D, Jayner CR. Effect of age on left ventricular filling in children of hypertensive parents. Am J Hypertens 1989. 2:792-6.

10. Hansen HS, Nielsen JS, Myldebrandt N, Froberg K. Blood pressure and cardiac structure in children with a parental history of hypertension: the Odense Schoolchild study. J Hypertens 1992; 10: 677-82.

I I. Allemann Y, Aeschbacher B, Zwyssig P, Ferrari P. Hopf M. Shaw G, et al. Left ventricular structure and determinants in normotensive offspring of essential hypertensive parents. J Hypertens 1992; 10: I 257-64.

12. O'Donnell CJ, Lindpaintner K, Larson MG, Rao VS, Ordovas JM, Schaefer EJ, et al. Evidence for association and genetic linkage of the angiotensin-converting enzyme locus with hypertesion and blood pressure in men but not women in the Framingham Heart Study. Circulation 1998; 97: | 766-72.

13. Ishigami T, Iwamoto T; Tamura K, Yamaguchi S, Iwasawa K, Uchino K, et al. Angiotensin I converting enzyme (ACE) gene polymorphism and essential hypertension in Japan ethnic difference of ACE genotype. Am J Hypertens 1995, 8:95-7.

14. Chrostowska M, Narkiewicz K, Bigda J, Winnicki M, Pawlowski R, Rossi GP, et al. Ambulatory systolic blood pressure is related to the deletion allele of the angiotensin I converting enzyme gene in young normotensives with parenteral history of hypertension. Clin Exp Hypertens 1998; 20:283-94.

I5. Nakano Y, Oshima T, Hiraga H, Matsuura H, Matsiura H, Kajujama G, Kambe M, et al. DD genotype of the angiotensin I-converting enzyme gene is a risk factor for early onset of essential hypertension in Japanese patients. Lab Clin Med 1998; 131:502-6. 
16. Maeda Y, Ikeda U, Ebata H, Hojo Y, Seino Y, Nakagami S, et al. Angiotensin converting enzyme gene polymorphism in essential hypertension based on ambulatory blood pressure monitoring. Am J Hypertens 1997; 10:786-9.

17. Abbud ZA, Wilson AC, Cosgrove NM, Kostis JB. Angiotensin-converting enzyme gene polymorphism in systemic hypertension. Am J Cardiol 1998; 81:244-6.

18. Chiang FT, Lai ZP, Chren TH, Tseng CD, Hsu KL, Tseng YZ, et al. Lack os association of the angiotensin converting enzyme polymorphism with essential hypertension in a Chinese population. Am J Hypertens 1997; 10:197-201.

19. Lindpaintner K, Lee M, Larson MG, Rao VS,
Pfeffer MA, Ordovas JM, et al. Absence of association or genetic linkage beteween the angiotensin- converting-enzyme gene and left ventricular mass. N Engl J Med 1996; 334: 1023-8.

20. West MJ, Summers KM, Wong KK, Schaeffer EJ, Burstow DJ. Renin-angiotensin system gene polymorphism and left ventricular hypertrophy. Adv Exp Med Biol 1997; 1 17:22-6.

21. Ghoraieb N, Batlouni M. Hipertrofia ventricular esquerda: mecanismos envolvidos na indução e possibilidades de regressão Rev Soc Cardiol Estado de São Paulo 1998; 8:298-30। .

22. Perticone F, Ceravolo R, Cosco C, Trapasso $M$, Zingone $A$, Malatesta $P$, et al. Deletion polymorphism of the angiotensin-converting enzyme gene and left ventricular hypertrophy in southern Italian patients. J Am Coll Cardiol 1997; 29:365-9.

23. Gaharavi AG, Lipkowitz MS, Diamond JÁ, Jhang JS, Phillips RA. Deletion polymorphism of the angiotensin-converting enzyme gene is independently associated with left ventricular mass and geometric remodeling in systemic hypertension. Am J Cardiol 1996, 77:1315-9.

Artigo recebido: 13/09/02 Aceito para publicação: 19/09/03 